\title{
Arterial and venous thrombosis complicating coronary artery bypass grafting after use of epoetin alfa-epbx
}

Alejandro Murillo-Berlioz, MD, ${ }^{a}$ Nicole R. Guinn, MD, ${ }^{\mathrm{b}}$ Jerrold H. Levy, MD, ${ }^{\mathrm{a}, \mathrm{b}}$ and Carmelo A. Milano, MD, ${ }^{\text {a }}$ Durham, NC

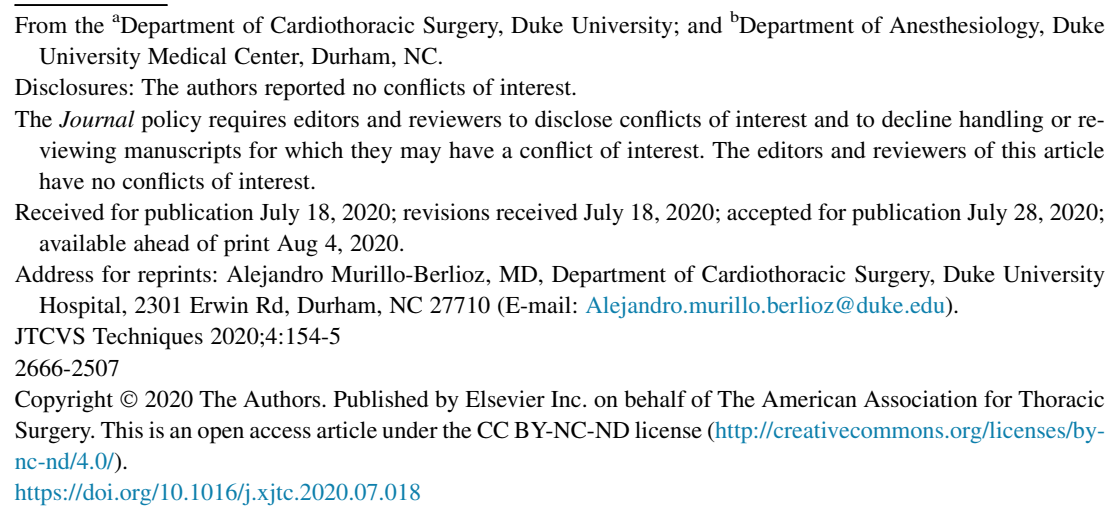

Epoetin alfa-epbx is one of the erythropoietin-stimulating agents (ESAs) produced using recombinant DNA technology that are used to treat anemia. In a perioperative setting, ESAs are administered to reduce allogeneic transfusion risk and increase red blood cell mass for surgical patients, including those unwilling or unable to receive transfusions. ${ }^{1}$ ESAs are recommended as a IIa recommendation in preoperative anemia-management guidelines for patients unwilling to receive transfusions. ${ }^{2,3}$ Clinical trials evaluating the cardiovascular benefits of epoetin-alfa with anemia and/or end-stage renal disease have reported variable thrombotic events, including in patients refusing transfusions where the benefits of treating anemia may outweigh potential thrombotic risks. A proposed mechanism for increased thrombotic events is an increase in platelet activation and thrombocytosis. ${ }^{4}$ We report a patient treated with epoetin alfa-epbx before coronary artery bypass grafting (CABG) who was at a low risk for perioperative thrombotic events but experienced both pulmonary and major arterial thrombotic complications postoperatively. Written informed consent was obtained.

\section{CLINICAL SUMMARY}

A 73-year-old African American female patient was evaluated for an elective CABG due to symptomatic, severe left main coronary artery disease. Her medical history included well-controlled hypertension, type 2 diabetes mellitus, transient ischemic attacks, and ischemia with a previous percutaneous coronary intervention and drug-eluting stent placed to the left anterior descending artery. She was a Jehovah's Witness and was evaluated by our bloodconservation program, which recommended preoperative intravenous iron supplementation, folate, vitamin B12,

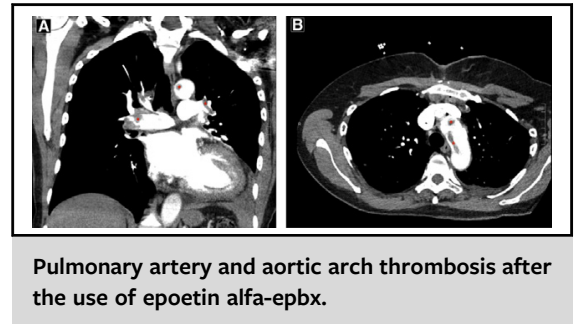

\begin{abstract}
CENTRAL MESSAGE
We would like to add to the evidence that the use of erythropoietin-stimulating agents for preoperative anemia in patients undergoing cardiac surgery may carry a substantial risk of thrombotic events.
\end{abstract}

See Commentaries on pages 156 and 158.

minimizing blood draws, and epoetin-alfa 300 units $/ \mathrm{kg}$ daily for 10 days to augment preoperative hemoglobin concentration. ${ }^{5}$

On admission to the hospital, her hemoglobin was $10.4 \mathrm{~g} /$ dL, 260,000 platelets, and otherwise-normal laboratory values. A heparin infusion was started for unstable angina, and after receiving 8 epoetin alfa-epbx and 5 ferric gluconate doses, she had ongoing chest pain and required urgent surgery. Hemoglobin and platelet count before surgery was $12.5 \mathrm{~g} / \mathrm{dL}$ and 207,000, respectively. She underwent an uneventful CABG 10 days after admission with a reversed saphenous vein graft bypass to an obtuse marginal branch of the circumflex coronary and pedicled left internal mammary artery to the distal left anterior descending coronary artery. Blood-conservation techniques used included cell salvage and acute normovolemic hemodilution maintaining the continuity of blood with the patient and tranexamic acid. Her postoperative course was unremarkable, and she was discharged on postoperative day 6 .

On postoperative day 10 , she presented to the emergency department complaining of shortness of breath, with an oxygen saturation of $79 \%$ on ambient air, subsequently requiring endotracheal intubation for mechanical ventilation. Hemoglobin and platelet counts were $12.0 \mathrm{~g} / \mathrm{dL}$ and 

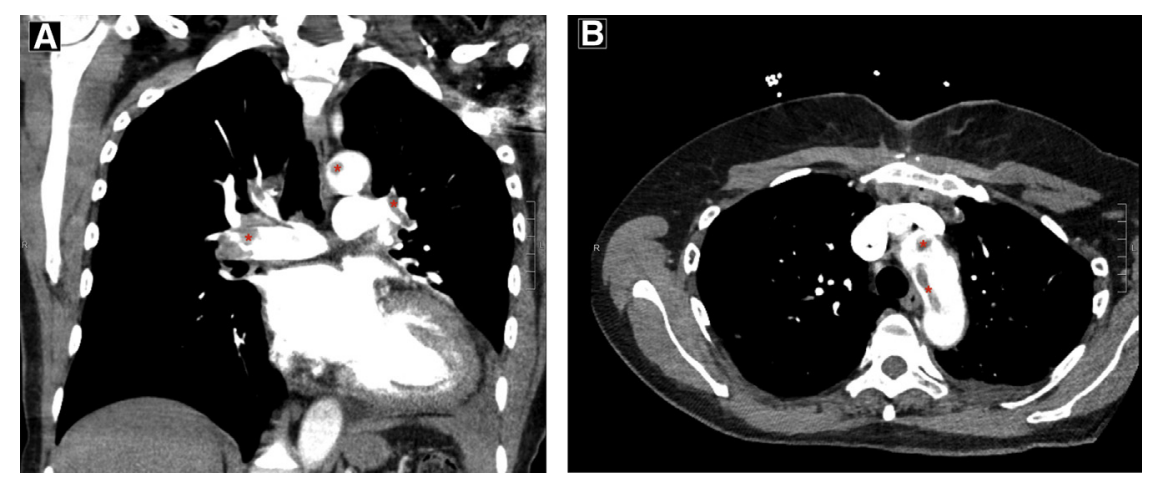

FIGURE 1. A 73-year-old patient treated with epoetin alfa-epbx for preoperative anemia before coronary artery bypass grafting presented 10 days after surgery with a submassive pulmonary embolism and aortic arch thrombosis. A, Coronal imaging showing thrombus $(*)$ in the right and left pulmonary artery, as well as in the aortic arch. B, Axial imaging showing thrombus $\left(^{*}\right)$ in the aortic arch.

419,000 respectively. Point-of-care testing for coronavirus disease 2019 (COVID-19) was negative. Axial imaging showed extensive bilateral pulmonary emboli and infarcts, as well as thrombus in the aortic arch and left common carotid artery (Figure 1). A transthoracic echocardiogram was notable for flattening of the interventricular septum, consistent with right ventricle overload and a pro-brain natriuretic peptide of 7000. A diagnosis of submassive pulmonary embolism was established, nitric oxide was administered for her hypoxemia, and the patient was taken to interventional radiology and underwent catheter-directed thrombectomy. She tolerated the procedure well and subsequently recovered in the cardiothoracic intensive care unit. She was transferred to a stepdown unit and continued to receive heparin anticoagulation and was transitioned to warfarin. Lowerextremity Doppler was negative for deep vein thrombosis. A hypercoagulable workup resulted negative for protein C and protein $\mathrm{S}$ deficiency, as well as negative titers for anti-beta 2 glycoprotein. Follow-up computed tomography of the chest demonstrated reduction in size of pulmonary artery and aortic thrombus. She was subsequently discharged on therapeutic anticoagulation with warfarin.

\section{DISCUSSION}

To our knowledge, this is the first reported case of simultaneous arterial and venous thrombosis in a patient who received preoperative ESAs before heart surgery, despite being determined to be low risk for thrombosis. Intraoperative transesophageal echocardiography testing with color Doppler and bubble study was negative for a patent foramen ovale. She received pre- and postoperative aspirin. Her thrombotic events occurred less than 7 days after her index procedure, and she tested negative for COVID-19, a potential cause. Further workup for prothrombotic conditions was also negative. Nonetheless, ESAs remain an important component of anemia treatment, particularly for those patients for whom transfusion is not an option, and the lowest effective dose should be used. As the use of epoetin-alfa becomes more common for patients with preoperative anemia, its benefits must be weighed against possible increased risk of major thrombotic events, and consideration should be given for the potential need for postoperative pharmacologic thrombosis prophylaxis.

\section{References}

1. Weltert L, Rondinelli B, Bello R, Falco M, Bellisario A, Maselli D, et al. A single dose of erythropoietin reduces perioperative transfusions in cardiac surgery: results of a prospective single-blind randomized controlled trial. Transfusion. 2015;55:1644-54.

2. Society of Thoracic Surgeons Blood Conservation Guideline Task Force, Ferraris VA, Brown JR, Despotis GJ, Hammon JW, Reece TB, et al. 2011 update to the Society of Thoracic Surgeons and the Society of Cardiovascular Anesthesiologists blood conservation clinical practice guidelines. Ann Thorac Surg. 2011;91:944-82.

3. Task Force on Patient Blood Management for Adult Cardiac Surgery of the European Association for Cardio-Thoracic Surgery (EACTS) and the European Association of Cardiothoracic Anaesthesiology (EACTA), Boer C, Meesters MI, Milojevic M, Benedetto U, Bolliger D, et al. 2017 EACTS/EACTA guidelines on patient blood management for adult cardiac surgery. J Cardiothorac Vasc Anesth. 2018;32:88-120.

4. Demetz G, Laux M, Scherhag A, Hoekstra T, Suttorp MM, Dekker F, et al. The influence of Erythropoietin on platelet activation, thrombin generation and FVII/active FVII in patients with AMI. Thromb J. 2014;12:18.

5. Mccartney S, Guinn N, Roberson R, Broomer B, White W, Hill S. Jehovah's Witnesses and cardiac surgery: a single institution's experience. Transfusion. $2014 ; 54: 2745-52$ 